\title{
LRH1 promotes tumor cell proliferation, migration and correlates with poor prognosis in ovarian cancer
}

\section{Wenzhou Sun}

Tumor Hospital of Harbin Medical University

Qingtao Shi

Tumor Hospital of Harbin Medical University

Jiaxin Li

Tumor Hospital of Harbin Medical University

Jinmeng Li

Tumor Hospital of Harbin Medical University

Libo Yu ( $\nabla$ ylb13030082698@sina.com )

harbin medical univeristy cancer hospital https://orcid.org/0000-0002-9111-8412

\section{Primary research}

Keywords: Liver receptor homolog 1 (LRH1); ovarian cancer; proliferation; metastasis; prognosis

Posted Date: May 11th, 2020

DOI: https://doi.org/10.21203/rs.3.rs-26942/v1

License: (c) (1) This work is licensed under a Creative Commons Attribution 4.0 International License. Read Full License 


\section{Abstract}

Background Recent studies have revealed that liver receptor homolog 1 (LRH1) plays a vital role in several human cancers, but its role in ovarian cancer (OC) remains unclear. We aimed to investigate whether $\mathrm{LRH} 1$ protein can act as a promising biomarker to predict the prognosis and metastasis in OC patients.

Methods LRH1 expression status was evaluated by immunohistochemical and reverse transcription (RT)qPCR analysis. The effects of LRH1 on tumor cell proliferation and progression were evaluated in vitro.

Results RT-qPCR showed that LRH1 mRNA expression was more intense in the invasive lesions $(P<0.05)$. LRH1 overexpression were extremely related with elevated FIGO stage $(P=0.001)$, lymph node metastasis $(P=0.011)$, and peritoneal metastasis $(P=0.001)$. Furthermore, LRH1 expression was an independently prognostic index for disease-free survival in OC patients $(P=0.041)$. In addition, LRH1 overexpression $(P=0.011)$ along with FIGO stage $(P<0.001)$ and ascites $(P=0.015)$ independently affect peritoneal metastasis in $\mathrm{OC}$ patients. $\mathrm{LRH} 1$ knockdown significantly inhibited the proliferation, migration, and metastasis of human $\mathrm{OC}$ cells $(P<0.05)$.

Conclusions The present study provides evidence that LRH1 predicts peritoneal metastasis and poor outcome, highlighting its potential role as biomarker for targeted therapy in OC.

\section{Background}

The incidence of ovarian cancer (OC) has showed a steady decrease during the past ten years in American, however its mortality rate remains high $[1,2]$. Surgery is the priority and standard treatment for OC. Recent years, even though novel technology has been applied for the diagnosis and treatment of OC, while the prognosis remain poor for advanced stage of OC [3]. We have gained insight on ovarian cancer in recent years although advancing knowledge has previously been hindered by substantial disease heterogeneity and uncertainties about tumor tissues of origin [2]. Therefore, it will be helpful to identify an ideal biological factor which predicts the malignant biological behavior and the prognosis of OC.

LRH1 (also known as nuclear receptor subfamily 5 group A member 2 NR5A2) participates in various biological processes: liver and pancreas differentiation, steroidogenesis in childhood, cholesterol/bile acid homeostasis, and tumor progression $[4,5]$. Previous studies have validated that overexpression of LRH1 may be induced resistance to chemotherapy of breast cancer [6], metastasis of pancreases cancer [7], poor prognosis of colon cancer [8] and non-small cell lung cancer [9], and proliferation of hepatoblastoma [10]. However, LRH1 expression in OC patients has not been reported so far.

Thus, we aimed to explore the status of LRH1 protein expression in $\mathrm{OC}$ and its clinical significance.

\section{Materials And Methods}




\section{Human tissue samples and clinical data}

133 OC tumor tissue samples were obtained from Harbin Medical University Cancer Hospital, who underwent cytoreductive surgery without any prior treatment for cancer such as chemotherapy or radiation between January 2009 and December 2011. The International Federation of Gynecology and Obstetrics (FIGO) staging system was applied to assess tumor stage [11]. Histological grades were appraised on the basis of the standard of the World Health Organization Histological Grading System for tumors [12]. Furthermore, to assess the status of lymph node, all included OC patients underwent lymph node dissection. Besides, 25 patients with normal ovaries who underwent hysterectomy with oophorectomy for benign uterine disease in our hospital during the same period were included.

Approval from the Medical Ethics Committee of Harbin Medical University Cancer Hospital was obtained for the purpose of research. $133 \mathrm{OC}$ patients were followed up for survival analyses until death or until the study closing date (January 2018).

\section{Immunohistochemical (IHC) staining and evaluation}

133 tissue blocks of $\mathrm{OC}$ and 25 of normal ovary tissues were cut by a microtome into $4-\mu \mathrm{m}$ sections and affixed onto the slide. After dewaxing in xylene and rehydrating through graded alcohol concentrations, the sections were incubated with $0.3 \%$ hydrogen peroxide for 10 minutes at room temperature to block endogenous peroxidase, and then the sections were incubated with anti-LRH1 antibody (1:100, Abcam, ab223211) overnight at $4^{\circ} \mathrm{C}$. After washing in phosphate-buffered saline (PBS), all sections were incubated with secondary antibodies (R\&D Systems, NL004) at room temperature for 20 min and then treated with 3,3'-diaminobenzidine tetrahydrochloride (Dako, Hamburg, Germany), following by counterstaining with hematoxylin.

Protein expression level of LRH1 was scored by evaluating the percentage of the positive staining areas of tumor cells together with intensity of staining. The former was scored as follows [9]: $0,<0 \% ; 1,1-10 \%$; $2,11-50 \% ; 3,51-70 \%$ and $4, \geq 70 \%$. The latter was scored as follows: 0 , negative staining; 1 , weak staining; 2 , moderate staining; and 3 , intense staining. The final expression level of LRH1 was semiquantitatively evaluated according to the sum of the scores for the percentage of positively stained tumors cells and intensity scores (0-7) in which the final staining scores of $0-3$ and 4-7 were considered to be low and high expression, respectively.

The IHC staining on each slide was scored in twice independently by two pathologists who were sophisticated in evaluating IHC and blinded with the clinicopathological information.

\section{Cell culture}

The human OC cell lines SKOV3 and OVCAR3 (ATCC) were employed. Both the cell lines have been approved by short tandem repeat (STR) profiling. Cells were cultured at $37^{\circ} \mathrm{C}$ in a humidified atmosphere containing 5\% CO2 in DMEM complemented with 10\% FBS and antibiotics (penicillin and streptomycin). Cells were passaged when they reached $80 \%$ confluence. 


\section{Western blotting analysis}

The cell lysates were both centrifuged at $13000 \mathrm{rpm}$ (at $4^{\circ} \mathrm{C}$ for 5 minutes). After that $10 \%$ sodium dodecyl sulfate polyacrylamide gel electrophoresis (SDS-PAGE) were used to segregate them, and then transferred onto polyvinylidene difluoride (PVDF) membranes (Millipore, Bedford, MA, USA).The filters were blocked with blocking buffer (Sangon Biotech) for 45 min.Membranes were incubated with Primary antibodies against LRH1 (Abcam, ab223211) at $4^{\circ} \mathrm{C}$ overnight, and with secondary antibodies at 1:5000 dilution at room temperature for $2 \mathrm{~h}$, following by incubating with $\beta$-actin (Abcam, ab179467) atroom temperature for $1.5 \mathrm{~h}$.

\section{RNA extraction and reverse transcription (RT)-qPCR}

The TRIzol ${ }^{\text {TM }}$ LS Reagent (Invitrogen ${ }^{T M}$ ) was used to extract total RNA from tissues and cells, according to the manufacturer's protocol, followed by complementary DNA synthesis using a PrimeScript RT reagent Kit with gDNA Eraser (Takara). Amplification was subsequently carried out using the GeneAmp ${ }^{\circledR} \mathrm{PCR}$ System 9700 (Applied Biosystems, USA). Real-time PCR was performed using LightCycler ${ }^{\circledR} 480 \otimes$ Realtime PCR Instrument (Roche, Swiss). The mRNA expression levels of LRH-1 were normalized to the mRNA levels of GAPDH, which was used as an internal control. The $2^{-\triangle \Delta C t}$ method was used to quantify the mRNA expression levels [13].

\section{Establishment of stable short hairpin (sh)RNA-mediated LRH-1 knockdown ovarian cancer cell lines}

shRNA-induced knockdown of LRH-1 expression was achieved using the lentiviral expression system. The plasmid used in the present study were pPLK/GFP + Puro-NR5A2 (Genomeditech, China). Viral particles were generated by co-transfecting 293T cells (ATCC) with the shRNAs and the GM easy ${ }^{\text {TM }}$ Lentivirus Packaging kit (Genomeditech, China), which contains packaging plasmids and a transfection reagent according to the manufacturer's protocol. Subsequently, the shRNA viral particles transfected SKOV3 and OVCAR3 cells with $4 \mu \mathrm{g} / \mathrm{mL}$ polybrene (Sigma-Aldrich), and stable cell lines were established after 10 days of puromycin $(2 \mu \mathrm{g} / \mathrm{ml})$ selection. Knockdown was confirmed using RT-qPCR or immunoblotting. The selected cell lines were routinely cultured in puromycin-containing media until 2 days prior to experimentation.

\section{Transwell assay}

For migration assays, infected OVCAR3 cells $\left(1 \times 10^{5}\right.$ in $200 \mu \mathrm{L}$ of serum-free DMEM medium) and SKOV3 cells $\left(1 \times 10^{5}\right.$ in $200 \mu \mathrm{L}$ of serum-free DMEM medium) were seeded into the upper chamber of transwell plates in a 24-well format with $8 \mu \mathrm{m}$ diameters (Corning Costar, USA). Then, $600 \mu \mathrm{L}$ of medium containing $10 \%$ FBS was added to the bottom chamber as a chemoattractant. After 24 hours of culture, cells were fixed with methanol and stained with Crystal Violet solution. The remaining cells were removed from the top of the permeable membrane using a cotton swab. Then, cells that migrated through the 
upper chamber were counted in 4 random fields under a light microscope (NIKON INSTRUMENTS(SHANGHAI)CO.,LTD).

\section{Wound healing assay}

OVCAR3 $\left(1 \times 10^{5}\right.$ cells $)$ and SKOV3 cells $\left(1 \times 10^{6}\right.$ cells $)$ were seeded in 6-well cell culture plates and incubated for 24 hours at $37^{\circ} \mathrm{C}$. After achieving confluence, the cellular layer in each plate was scratched using a plastic pipette tip. The migration of the cells at the edge of the scratch was analyzed at 0 and 24 hours, when microscopic images of the cells were captured.

\section{Cell counting kit-8 (CCK-8)}

SKOV3 and OVCAR3 cells were plated in flat-bottom 96-well plates (1500 and 1000 cells/well) and supplemented with $100 \mu \mathrm{L}$ DMEM medium with $10 \% \mathrm{FBS}$ per well. After incubation at $37^{\circ} \mathrm{C}$ in a humidified incubator with 5\% CO2 for 2, 24, 48, 72, and 96 hours, respectively, $10 \mu \mathrm{L}$ of CCK-8 (Yeasen Biotech Co., Ltd.) was added to each well. Then, after 1 hours of culture, colorimetric analysis was performed on a microplate reader (Thermo Scientific ${ }^{\text {TM }}$ Varioskan $^{\text {TM }}$ LUX) at a wavelength of $450 \mathrm{~nm}$. The assay was performed using six replicates.

\section{Statistical analysis}

The chi-square test was used to analyze the statistical differences of the clinicopathologic variables. Overall survival (OS) and disease-free survival (DFS) were evaluated by the Kaplan-Meier method and logrank test. The Cox proportional hazards model was used to estimate the independent prognostic factors for survival. Logistic regression was performed for multivariate analysis of the association between LRH1 expression and intraperitoneal metastasis. Student's t-test were used to analyze the differences between the experimental and control groups. A two-sided $\mathrm{P}<0.05$ was considered significant.

\section{Results}

\section{Expression level of LRH1 in OC tissues}

RT-qPCR was carried out to identify the discrepancy between LRH1 mRNA expression in OC and normal ovarian tissues (Figure. 1). No discrepancy was observed between LRH1 expression in normal tissues and that in $\mathrm{OC}$ tissues $(P>0.05)$. However, LRH1 protein in OC with metastasis presents (T2) higher expression than that in OC without metastasis $(\mathrm{T} 1)(P=0.017)$. Moreover, the status of LRH1 mRNA expression was more intense in the invasive foci (M) than in the situ foci (T2) among the same patients $(P=0.034)$.

IHC revealed that the expression of LRH1 in normal tissues were scarcely detectable, however, LRH1 in OC tissues was stained intensely (Figure. 2). As shown in Fig. 2B, LRH1 was observed both in both the nucleus and cytoplasm of tumor cells. However, LRH1 was mainly localized in the nucleus of tumor cells. Of the OC specimens examined, low LRH1 expression was detected in 59 of 133 (44.4\%) patients, and high LRH1 expression was detected in 74 of 133 (55.6\%) patients. 


\section{Relationship of elevated LRH1 protein expression with clinicopathologic variables}

Table 1 summarizes the association between LRH1 expression and clinicopathological variables in OCs. LRH1 expression significantly related with the FIGO stage $(P=0.001)$, lymph node metastasis $(P=0.011)$, and intraperitoneal metastasis $(P=0.001)$. No relationships of $\mathrm{LRH} 1$ with age, histological type, histologic grade, residual disease, ascites, or serum CA-125 level were observed $(P>0.05)$. 
Table 1

Correlation between LRH1 protein expression level and clinicopathological variables in 133 patients with $\mathrm{OC}$

\begin{tabular}{|c|c|c|c|c|}
\hline \multirow[t]{3}{*}{ Variables } & \multirow{3}{*}{$\begin{array}{l}\text { All patients } \\
n=133\end{array}$} & \multicolumn{2}{|c|}{ LRH1 expression level } & \multirow[t]{3}{*}{$P$} \\
\hline & & Low (\%) & High (\%) & \\
\hline & & $(n=59)$ & $(n=74)$ & \\
\hline Age (years) & 67 & 33 (49.3) & $34(50.7)$ & 0.252 \\
\hline$\leq 52$ & 66 & $26(39.4)$ & $40(60.6)$ & 0.653 \\
\hline$>52$ & 92 & $42(45.7)$ & $50(54.3)$ & 0.001 \\
\hline Histological type & 41 & $17(41.5)$ & $24(58.5)$ & 0.310 \\
\hline Serous & 28 & $20(71.4)$ & $8(28.6)$ & 0.851 \\
\hline Others & 105 & $39(37.1)$ & $66(62.9)$ & 0.473 \\
\hline FIGO stage & 50 & $25(50.0)$ & $25(50.0)$ & 0.653 \\
\hline I/II & 83 & $34(41.0)$ & $49(59.0)$ & 0.011 \\
\hline III/IV & 98 & $43(43.9)$ & $55(56.1)$ & 0.001 \\
\hline Histologic grade & 35 & $16(45.7)$ & $19(54.3)$ & \\
\hline $\mathrm{G} 1 / \mathrm{G} 2$ & 38 & $15(39.5)$ & $23(60.5)$ & \\
\hline G3 & 95 & $44(46.3)$ & $51(53.7)$ & \\
\hline Residual disease $(\mathrm{cm})$ & 41 & $17(41.5)$ & $24(58.5)$ & \\
\hline$<1$ & 92 & $42(45.7)$ & $50(54.3)$ & \\
\hline$\geq 1$ & 81 & $43(53.1)$ & $38(46.9)$ & \\
\hline Ascites (ml) & 52 & $16(30.8)$ & $36(69.2)$ & \\
\hline$<100$ & 43 & $28(65.1)$ & $15(34.9)$ & \\
\hline$\geq 100$ & 90 & $31(34.4)$ & 59 (65.6) & \\
\hline \multicolumn{5}{|c|}{ Serum CA-125 level (U/ml) } \\
\hline \multicolumn{5}{|l|}{$\leq 35$} \\
\hline \multicolumn{5}{|l|}{$>35$} \\
\hline \multicolumn{5}{|l|}{ Lymph node metastasis } \\
\hline \multicolumn{5}{|l|}{ No } \\
\hline \multicolumn{5}{|l|}{ Yes } \\
\hline $\begin{array}{l}\text { FIGO the Federation o } \\
\text { differentiated, G3 poo }\end{array}$ & d Obstetric & ll differen & G2 moder & \\
\hline
\end{tabular}




\begin{tabular}{|llll|}
\hline Variables & All patients & \multicolumn{2}{l|}{ LRH1 expression level }
\end{tabular}

Peritoneum metastasis

No

Yes

FIGO the Federation of Gynaecology and Obstetrics, G1 Well differentiated, G2 moderately differentiated, G3 poorly differentiated, OC ovarian cancer

\section{LRH1 increased expression in OC predicts an unfavorable prognosis especially recurrence}

The log-rank test showed that patients with low LRH1 expression had a significantly better OS and DFS compared to patients with high LRH1 expression ( $P=0.007$ and $P<0.001$, Fig. 3$)$. In addition to LRH1, FIGO stage (both $P<0.001)$, histologic grade $(P=0.009$ and $P=0.028$, respectively), residual disease $P=$ 0.022 and $P=0.026$, respectively), lymph node metastasis (both $P<0.001$ ), and intraperitoneal metastasis ( $P=0.001$ and $P<0.001$, respectively) are correlated with prognosis of OC (Table 2). Furthermore, displayed in Table 2, multivariate Cox regression analysis showed that the high LRH1 expression was considered as an independent prognostic marker for DFS of patients with OC instead of OS $(P=0.041)$. 
Table 2

Univariate and multivariate analyses for survival in $133 \mathrm{OC}$ patients

\begin{tabular}{|llll|}
\hline Variables & Univariate & Multivariate & \\
\cline { 2 - 4 } & $\boldsymbol{P}$ & HR 95\%Cl $\boldsymbol{P}$ & \\
\hline variables related to OS & 0.219 & $3.695(1.793-7.613)$ & 0.001 \\
Age (years) & 0.914 & $1.664(1.101-2.513)$ & 0.016 \\
Histological type & $<0.001$ & $1.682(1.093-2.591)$ & $<0.001$ \\
FIGO stage & 0.009 & $3.665(2.344-5.730)$ & 0.001 \\
Histologic grade & 0.022 & $3.437(1.641-7.200)$ & 0.038 \\
Residual disease (cm) & 0.696 & $1.550(1.024-2.345)$ & 0.025 \\
Ascites (ml) & 0.154 & $1.663(1.065-2.597)$ & 0.001 \\
Serum CA-125 level (U/ml) & $<0.001$ & $3.857(2.431-6.120)$ & \\
Lymph node metastasis & 0.001 & $1.535(1.017-2.318)$ & \\
Peritoneum metastasis & 0.007 & & \\
LRH1 expression level & 0.487 & & \\
variables related to DFS & 0.895 & & \\
Age (years) & $<0.001$ & & \\
Histological type & 0.028 & & \\
FIGO stage & 0.026 & & \\
Histologic grade & 0.855 & & \\
Residual disease (cm) & 0.281 & & \\
Ascites (ml) & $<.001$ & & \\
Serum CA-125 level (U/ml) & & & \\
Lymph node metastasis & & & \\
Peritoneum metastasis & & & \\
LRH1 expression level & & & \\
\hline & & & \\
& & & \\
\end{tabular}

FIGO the Federation of Gynaecology and Obstetrics, OS overall survival, DFS disease-free survival, OC ovarian cancer, HR hazard ratio, Cl confidence interval

LRH1 increased expression was an indicator for intraperitoneal and lymph node metastasis in OC 
To evaluate the relationship between LRH1 overexpression and intraperitoneal metastasis, traditional clinicopathological parameters about intraperitoneal metastasis were first appraised (Table 3). Univariate analyses of clinicopathologic variables for the metastasis of the intraperitoneal showed that the presence of intraperitoneal metastasis was positively associated with FIGO stage $(P<0.001)$, residual disease $(P=$ $0.025)$, and ascites $(P=0.019)$. Multivariate logistic regression analysis revealed that FIGO stage $(P=$ 0.003), residual disease $(P=0.032)$, and LRH1 $(P=0.010)$ were independently linked with intraperitoneal metastasis. 
Table 3

Univariate and multivariable analyses for the relationship between LRH1 expression and lymph node metastasis in OCs

\begin{tabular}{|c|c|c|c|c|c|c|}
\hline \multirow[t]{2}{*}{ Variables } & \multirow[t]{2}{*}{ No. } & \multicolumn{2}{|c|}{$\begin{array}{l}\text { Lymph node } \\
\text { metastasis }\end{array}$} & \multirow[t]{2}{*}{$\mathbf{P}$} & \multirow[t]{2}{*}{ OR $(95 \% \mathrm{Cl})$} & \multirow[t]{2}{*}{$\mathbf{P}$} \\
\hline & & Negative & Positive & & & \\
\hline Age (years) & & 40 & 27 & 0.775 & \multirow{21}{*}{$\begin{array}{l}2.421(1.109- \\
5.285) \\
2.451(1.162- \\
5.173)\end{array}$} & 0.026 \\
\hline$\leq 52$ & & 41 & 25 & 0.991 & & \multirow[t]{20}{*}{0.019} \\
\hline$>52$ & & 56 & 36 & 0.016 & & \\
\hline Histological type & & 25 & 16 & 0.595 & & \\
\hline Serous & & 37 & 13 & 0.653 & & \\
\hline Others & & 44 & 39 & 0.991 & & \\
\hline Histologic grade & & 61 & 37 & 0.011 & & \\
\hline $\mathrm{G} 1 / \mathrm{G} 2$ & & 20 & 15 & & & \\
\hline G3 & & 22 & 16 & & & \\
\hline Residual disease (cm) & & 59 & 36 & & & \\
\hline$<1$ & & 25 & 16 & & & \\
\hline$\geq 1$ & & 56 & 36 & & & \\
\hline Ascites (ml) & & 43 & 16 & & & \\
\hline$<100$ & & 38 & 36 & & & \\
\hline \multicolumn{4}{|l|}{$\geq 100$} & & & \\
\hline \multicolumn{4}{|l|}{$\begin{array}{l}\text { Serum CA-125 level } \\
(\mathrm{U} / \mathrm{ml})\end{array}$} & & & \\
\hline \multicolumn{4}{|l|}{$\leq 35$} & & & \\
\hline \multicolumn{4}{|l|}{$>35$} & & & \\
\hline \multicolumn{4}{|l|}{ LRH1 expression level } & & & \\
\hline \multicolumn{4}{|l|}{ Low } & & & \\
\hline High & & & & & & \\
\hline
\end{tabular}

Using the same method, the results showed that the presence of lymph node metastasis was significantly correlated with the histologic grade $(P=0.016)$ and $\mathrm{LRH} 1$ expression $(P=0.011)$. Multivariate logistic 
regression that histologic grade $(P=0.026)$ and $\mathrm{LRH} 1$ expression $(P=0.019)$ significantly led to lymph node metastasis (Table 4). 
Table 4

Univariate and multivariable analyses for the relationship between LRH1 expression and peritoneum metastasis in OCs

\begin{tabular}{|lllll|}
\hline Variables & No. $\begin{array}{l}\text { Peritoneum } \\
\text { metastasis }\end{array}$ & OR $(95 \% \mathrm{Cl})$ & $\mathrm{P}$ \\
\cline { 2 - 3 } & Negative Positive & & \\
\hline
\end{tabular}

FIGO the Federation of Gynaecology and Obstetrics, OC ovarian cancer, HR hazard ratio, Cl confidence interval 


\begin{tabular}{|c|c|c|c|c|c|c|}
\hline \multirow[t]{2}{*}{ Variables } & \multirow[t]{2}{*}{ No. } & \multicolumn{2}{|c|}{$\begin{array}{l}\text { Peritoneum } \\
\text { metastasis }\end{array}$} & \multirow[t]{2}{*}{$\mathbf{P}$} & \multirow[t]{2}{*}{ OR $(95 \% \mathrm{Cl})$} & \multirow[t]{2}{*}{$\mathbf{P}$} \\
\hline & & Negative & Positive & & & \\
\hline Age (years) & & 22 & 45 & \multirow{24}{*}{$\begin{array}{l}0.900 \\
0.918 \\
< \\
0.001 \\
0.064 \\
0.025 \\
0.019 \\
0.614 \\
0.001\end{array}$} & \multirow{24}{*}{$\begin{array}{l}4.613(1.678- \\
12.677) \\
3.208(1.104-9.322) \\
3.160(1.323-7.545)\end{array}$} & \multirow{24}{*}{$\begin{array}{l}0.003 \\
0.032 \\
0.010\end{array}$} \\
\hline$\leq 52$ & & 21 & 45 & & & \\
\hline$>52$ & & 30 & 62 & & & \\
\hline Histological type & & 13 & 28 & & & \\
\hline Serous & & 19 & 9 & & & \\
\hline Others & & 24 & 81 & & & \\
\hline FIGO stage & & 21 & 29 & & & \\
\hline $\mathrm{I} / \mathrm{II}$ & & 22 & 61 & & & \\
\hline III/IV & & 37 & 61 & & & \\
\hline Histologic grade & & 6 & 29 & & & \\
\hline $\mathrm{G} 1 / \mathrm{G} 2$ & & 18 & 20 & & & \\
\hline G3 & & 25 & 70 & & & \\
\hline Residual disease $(\mathrm{cm})$ & & 12 & 29 & & & \\
\hline$<1$ & & 31 & 61 & & & \\
\hline$\geq 1$ & & 28 & 31 & & & \\
\hline Ascites (ml) & & 15 & 59 & & & \\
\hline \multicolumn{4}{|l|}{$<100$} & & & \\
\hline \multicolumn{4}{|l|}{$\geq 100$} & & & \\
\hline \multicolumn{4}{|l|}{$\begin{array}{l}\text { Serum CA-125 level } \\
(\mathrm{U} / \mathrm{ml})\end{array}$} & & & \\
\hline \multicolumn{4}{|l|}{$\leq 35$} & & & \\
\hline \multicolumn{4}{|l|}{$>35$} & & & \\
\hline \multicolumn{4}{|l|}{ LRH1 expression level } & & & \\
\hline \multicolumn{4}{|l|}{ Low } & & & \\
\hline \multicolumn{4}{|l|}{ High } & & & \\
\hline $\begin{array}{l}\text { FIGO the Federation of } \\
\text { interval }\end{array}$ & & $y$ and Obs & ics, OC o & ian can & HR hazard ratio, $\mathrm{Cl} \mathrm{cc}$ & idence \\
\hline
\end{tabular}




\section{Knockdown of LRH1 inhibits OC cells proliferation and migration in vitro}

LRH1 knockdown assays using sh-RNA was conducted to investigate the biological function of LRH1 in OC cells. We used RT-qPCR and Western blotting to confirm that LRH1 expression in OVCAR3 and SKOV3 with sh-LRH1 transfection was significantly lower than that with sh-NC transfection (Fig. 4A and B). We explored the effect of knockdown of LRH1 on cell proliferation in OVCAR3 and SKOV3 cells. Compared with OVCAR3 and SKOV3 cells infected with sh-NC, the proliferation of OVCAR3 and SKOV3 cells infected with sh-LRH1 was repressed at 24, 48, 72, and 96 hours, respectively (Fig. 4C). Thus, knockdown of LRH1 significantly repressed cell proliferation.

We also investigate the effect of LRH1 on migration. Migrated cells through the transwell plates were counted in three random fields, and the average value of the three fields was calculated. The result of transwell assay showed that knockdown of LRH1 decreased the migration of SKOV3 and OVCAR3 cells by approximately $43 \%$ and $50 \%$, respectively (Fig. 4D). Wound-healing assay showed that LRH1 promoted cell migration in the SKOV3 and OVCAR3 cells (Fig. 4E). After $24 \mathrm{~h}$, SKOV3 and OVCAR3 control cells migrated approximately $20 \mathrm{~mm}$ and $12 \mathrm{~mm}$, respectively and SKOV3 and OVCAR3 with LRH1 knockdown migrated approximately $13 \mathrm{~mm}$ and $8 \mathrm{~mm}$, respectively. Cells with LRH1 knockdown shows less motility than control cells, indicating that LRH1 could stimulate cell migration.

\section{Discussion}

The new diagnosed cases and deaths of ovarian cancer will respectively be 22,240

and 14,070 in the United States. OC involves a heterogenous group of malignancies that differ from etiology, molecular biology, and other characteristics [2]. OC is the most common malignant tumor. Highrisk ovarian carcinoma patients have very low cure rates, despite therapy comprised of combined treatments, including surgery, chemotherapy and radiation [2]. Clearly, identification of novel biomarkers and more effective therapies is extremely urgent.

$\mathrm{LRH} 1$ is a member of the nuclear receptor NR5A (Ftz-F1) subfamily which expresses in endodermal origin tissues containing the intestine, liver, exocrine pancreas [14], ovary [15-18], pre-adipocyte [19], and placenta [20]. Recent studies have reported that LRH1 protein functioned as a cancer regulator which exist in extensive procedures, such as cell proliferation, chemotherapy resistance, and tumor progress [6, 21,22 ]. In the present study, we noticed that LRH1 protein expression showed high expression in OC tissues. Moreover, it indicated an increased trend of LRH1 protein and mRNA expression from T1 to T2 and its matched $\mathrm{M}$. This study firstly identified overexpression of $\mathrm{LRH} 1$ in $\mathrm{OC}$ tissues. Preceding studies showed similar result in non-small cell lung cancer tissues and colon cancer tissues. Liu et al. [9] demonstrated that LRH1 was highly overexpressed in non-small cell lung cancer tissues compared with normal tissues. Wu et al. [8] carried out IHC in colon cancer tissues to test LRH1 expression, which indicated that comparing with the adjacent normal tissues, the protein level of $\mathrm{LRH} 1$ was outstandingly 
elevated in the cancerous tissues. Additionally, Jin et al. [10] verified LRH1 expression in three hepatoblastoma cell lines, HepG2, HuH6 and HepT1, and one control cell line, THLE-2 by western blotting and found that LRH1 expression was also remarkably upgraded in HepG2 cells and HuH6 cells. Thus, LRH1 may provide a candidate molecular marker for malignant behavior of tumor.

A number of studies have viewed LRH1 as a significant prognosis biomarker for tumor invasion and proliferation in several carcinomas, for example pancreases cancer [23]. Enlightened by these researches, we were prompted to identify the role of LRH1 overexpression as a predictor for clinicopathological and prognostic significance. We recognized that elevated LRH1 protein expression was tremendously corresponded with FIGO stages, lymph node metastasis and intraperitoneal metastasis. Furthermore, multivariate logistic regression model demonstrated that high standard of LRH1 expression was significantly associated with lymph node metastasis and intraperitoneal metastasis. In addition, the OS periods in patients with high LRH1 expression were shorter than that in patients with low LRH1 expression. Oppositely, patients whose LRH1 expression is low presented better prognoses than those with high LRH1 expression. Wang et al. [24] adopted bioinformatics analysis to screen on the focus of the nuclear receptor (NR) family. They found that overexpression of these orphan NRs could increase cancer stem cell markers expression and enhanced spheroid formation capacity in prostate cancer cells. Moreover, they concluded that LRH1 could be the potential therapeutic targets for PCSCs or castrationresistant prostate cancer.

The mechanism of LRH1 influencing tumorigenesis, cell proliferation, migration, chemotherapy resistance varies in different kinds of cancers. Our study showed that LRH1 down-regulation inhibited OC cells proliferation and migration in vitro. In pancreases cancer, Lin et al. [7] have demonstrated that LRH1 enhanced transcriptional activity of $\beta$-catenin and up-regulated the expression of downstream target genes (c-Myc, MMP2/9), thus promoted migration and invasion. In breast cancer, it has found that MDC1 transcription was promoted by LRH1 through directly activating MDC1 promoter and resulting in elevated $\mathrm{YH} 2 \mathrm{AX}$ levels. Furthermore, the mRNA level of LRH1 and MDC1 were positively correlated in recurrent breast cancer samples. In addition, LRH1 promoted breast cancer cell chemoresistance by enhancing the expression of MDC1 and attenuating DNA damage [6]. All of these findings suggest an important biological role of LRH1 in carcinogenesis and tumor progression.

\section{Conclusion}

Although limitations still exist in this study, the present results we observed showed that LRH1 contributes to the lymph node metastasis, intraperitoneal metastasis and poor prognosis in OC, which indicated that $\mathrm{LRH} 1$ could be a specific biomarker for predicting poor prognosis and metastasis.

\section{Abbreviations}

LRH1: liver receptor homolog 1; OC: ovarian cancer; RT: reverse transcription; FIGO: the International Federation of Gynecology and Obstetrics; PBS: phosphate-buffered saline; IHC: Immunohistochemical; 
STR: short tandem repeat; SDS-PAGE: sodium dodecyl sulfate polyacrylamide gel electrophoresis; PVDF: polyvinylidene difluoride; OS: Overall survival; DFS: disease-free survival

\section{Declarations}

\section{Authors' contributions:}

YLB conceived and designed the study. LJX and LJM collected samples and processed data. SQT provided technical support. SWZ and YLB analyzed data. SWZ drafted the manuscript. YLB revised the manuscript. All authors read and approved the final manuscript.

Acknowledgements: Not applicable.

\section{Competing interests:}

The authors declare that they have no competing interests.

\section{Availability of data and materials:}

All data generated and analyzed during this study are included in this published article and its additional file.

\section{Consent for publication:}

Not applicable.

\section{Ethics approval and consent to participate:}

The current study was approved by the Ethics Committee of Harbin Medical University Cancer Hospital. A written consent from each participant was obtained after they were informed the purpose of this study.

\section{Funding:}

This study was supported by the Science and Technology Project of Education Department of Heilongjiang Province (12531275).

\section{References}

1. Siegel RL, Miller KD, Jemal A (2019) Cancer statistics, 2019. CA: a cancer journal for clinicians 69(1):7-34.

2. Torre LA, Trabert B, DeSantis CE, et al (2018) Ovarian cancer statistics, 2018. CA: a cancer journal for clinicians 68(4):284-96.

3. Doubeni CA, Doubeni AR, Myers AE (2016) Diagnosis and Management of Ovarian Cancer. American family physician 93(11):937-44. 
4. Lee YK, Moore DD (2008) Liver receptor homolog-1, an emerging metabolic modulator. Frontiers in bioscience : a journal and virtual library 13:5950-8.

5. Fayard E, Auwerx J, Schoonjans K (2004) LRH-1: an orphan nuclear receptor involved in development, metabolism and steroidogenesis. Trends in cell biology 14(5):250-60.

6. Wang S, Zou Z, Luo X, et al (2018) LRH1 enhances cell resistance to chemotherapy by transcriptionally activating MDC1 expression and attenuating DNA damage in human breast cancer. Oncogene 37(24):3243-59.

7. Lin Q, Aihara A, Chung W, et al (2014) LRH1 promotes pancreatic cancer metastasis. Cancer Lett 350(1-2):15-24.

8. Wu C, Feng J, Li L, et al (2018) Liver receptor homologue 1, a novel prognostic marker in colon cancer patients. Oncol Lett 16(3):2833-8.

9. Liu Y, Xing Y, Wang H, et al (2018) LRH1 as a promising prognostic biomarker and predictor of metastasis in patients with non-small cell lung cancer. Thorac Cancer 9(12):1725-32.

10. Jin J, Jin J, Woodfield SE, et al (2019) Targeting LRH1 in hepatoblastoma cell lines causes decreased proliferation. Oncol Rep 41(1):143-53.

11. Benedet JL, Bender $\mathrm{H}$, Jones $\mathrm{H}$, et al (2000) FIGO staging classifications and clinical practice guidelines in the management of gynecologic cancers. FIGO Committee on Gynecologic Oncology. International journal of gynaecology and obstetrics: the official organ of the International Federation of Gynaecology and Obstetrics 70(2):209-62.

12. Penzel R, Hoegel J, Schmitz W, et al (2003) Clusters of chromosomal imbalances in thymic epithelial tumours are associated with the WHO classification and the staging system according to Masaoka. International journal of cancer 105(4):494-8.

13. Livak KJ, Schmittgen TD (2001) Analysis of relative gene expression data using real-time quantitative PCR and the 2(-Delta Delta C(T)) method. Methods 25: 402-8.

14. Lu TT, Repa JJ, Mangelsdorf DJ (2001) Orphan nuclear receptors as eLiXiRs and FiXeRs of sterol metabolism. The Journal of biological chemistry 276(41):37735-8.

15. Boerboom D, Pilon N, Behdjani R, et al (2000) Expression and regulation of transcripts encoding two members of the NR5A nuclear receptor subfamily of orphan nuclear receptors, steroidogenic factor-1 and NR5A2, in equine ovarian cells during the ovulatory process. Endocrinology 141(12):4647-56.

16. Schoonjans K, Annicotte JS, Huby T, et al (2002) Liver receptor homolog 1 controls the expression of the scavenger receptor class B type I. EMBO reports 3(12):1181-7.

17. Hinshelwood MM, Repa JJ, Shelton JM, et al (2003) Expression of LRH-1 and SF-1 in the mouse ovary: localization in different cell types correlates with differing function. Molecular and cellular endocrinology 207(1-2):39-45.

18. Liu DL, Liu WZ, Li QL, et al (2003) Expression and functional analysis of liver receptor homologue 1 as a potential steroidogenic factor in rat ovary. Biology of reproduction 69(2):508-17. 
19. Clyne CD, Speed CJ, Zhou J, et al (2002) Liver receptor homologue-1 (LRH-1) regulates expression of aromatase in preadipocytes. The Journal of biological chemistry 277(23):20591-7.

20. Sirianni R, Seely JB, Attia G, et al (2002) Liver receptor homologue-1 is expressed in human steroidogenic tissues and activates transcription of genes encoding steroidogenic enzymes. The Journal of endocrinology 174(3):R13-7.

21. Li C, Dong J, Han Z, Zhang K (2017) MicroRNA-219-5p Represses the Proliferation, Migration, and Invasion of Gastric Cancer Cells by Targeting the LRH-1/Wnt/ $\beta$-Catenin Signaling Pathway. Oncology research 25(4):617-27.

22. Pang JB, Molania R, Chand A, et al (2017) LRH-1 expression patterns in breast cancer tissues are associated with tumour aggressiveness. Oncotarget 8(48):83626-36.

23. Lin Q, Aihara A, Chung W, et al (2014) LRH1 as a driving factor in pancreatic cancer growth. Cancer Lett 345(1):85-90.

24. Wang Z, Wu D, Ng CF, et al (2018) Nuclear receptor profiling in prostatospheroids and castrationresistant prostate cancer. Endocrine-related cancer 25(1):35-50.

\section{Figures}

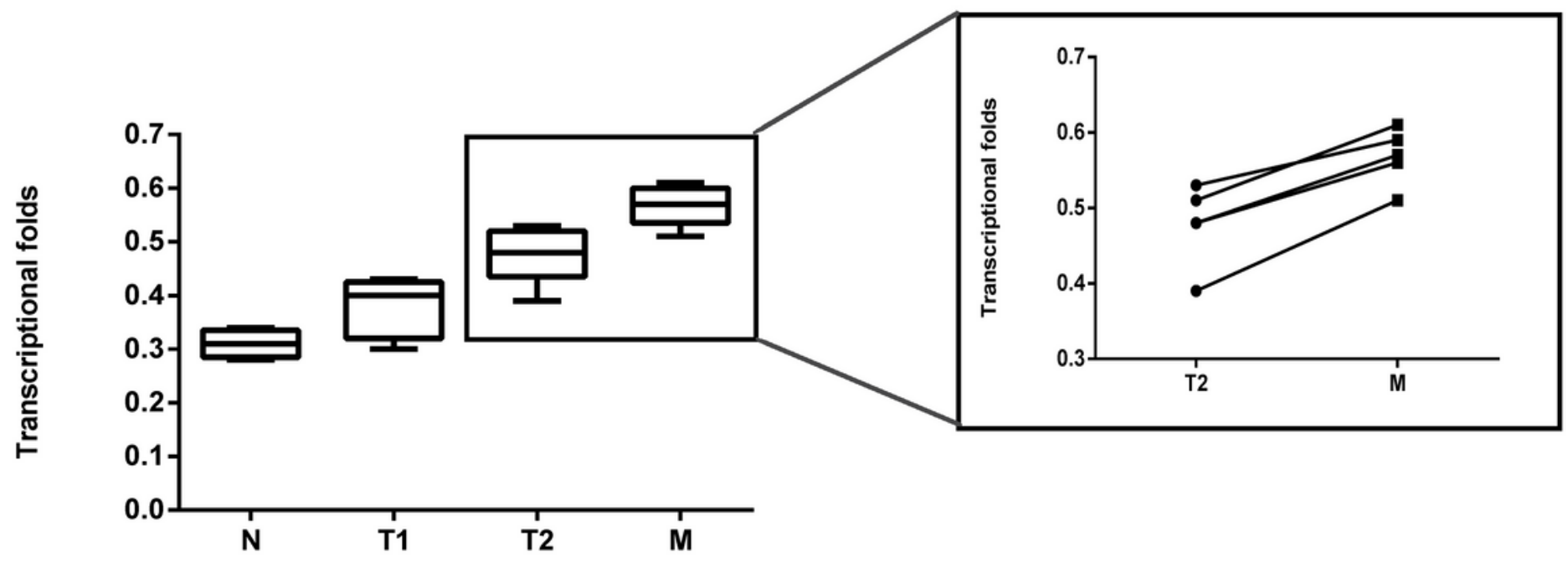

\section{Figure 1}

Real time PCR assay of LRH1 mRNA expression in $N, T 1, T 2$, and its matched $M$. It showed that elevated trend of LRH1 mRNA expression from $N$ to $T 1, T 2$ and its matched $M(P<0.05)$.

\section{Figure 2}

Immunohistochemical anlaysis of LRH1 protein expression (x 400). A negative or weak expression in normal ovarian tissues; $B$ high expression in primary ovarian cancer $(\mathrm{OC})$ tissues (observed mainly in 
nucleus, a few in cytoplasmic); C low expression in serous histotypes (mainly in nucleus); D high expression in serous histotypes (mainly in nucleus, a few in cytoplasmic); E high expression in mucinous histotypes (mainly in nucleus); $F$ high expression in endometrioid histotypes (mainly in nucleus, a few in cytoplasmic); $\mathrm{G}$ negative or low expression in clear cell histotypes; $\mathrm{H}$ high expression in clear cell histotypes (mainly in nucleus, scarcely in cytoplasmic).

A

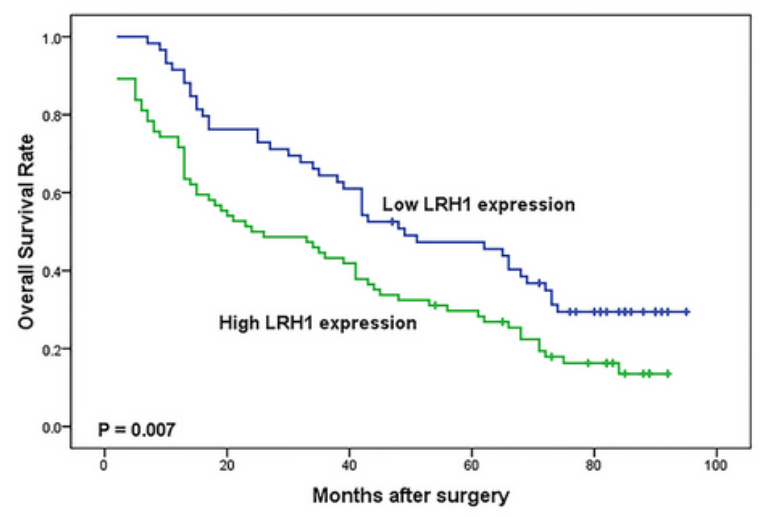

B

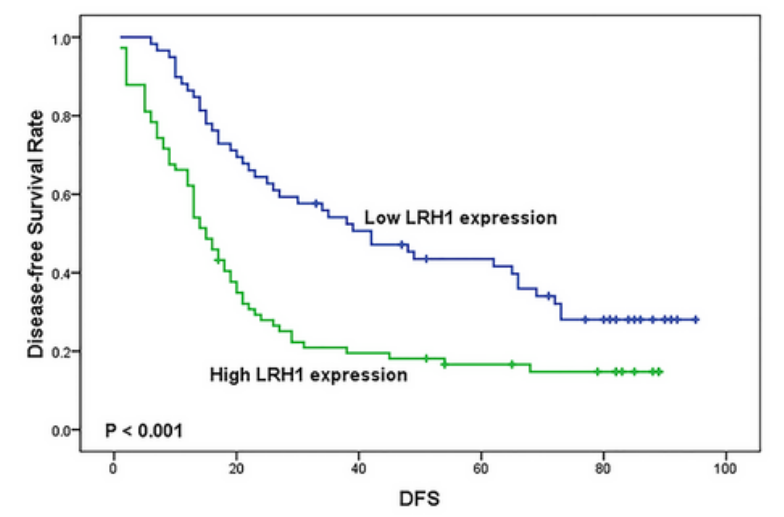

\section{Figure 3}

Kaplan-Meier analysis of overall survival (OS) and disease-free survival (DFS) related to the expression of LRH1. A OS curves of the $133 \mathrm{OC}$ patients; B DFS curves of the $133 \mathrm{OC}$ patients. 

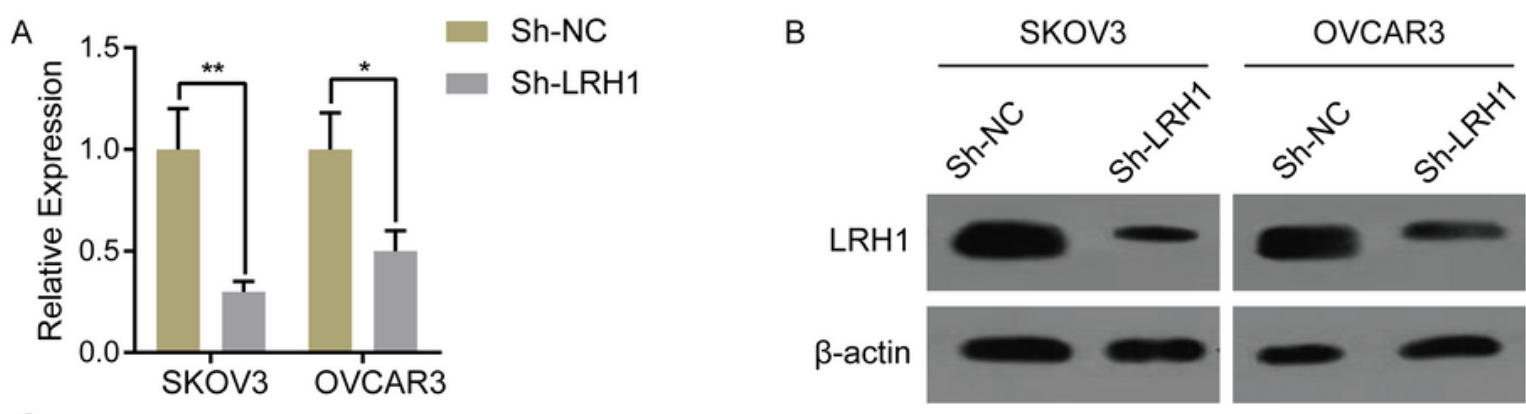

C
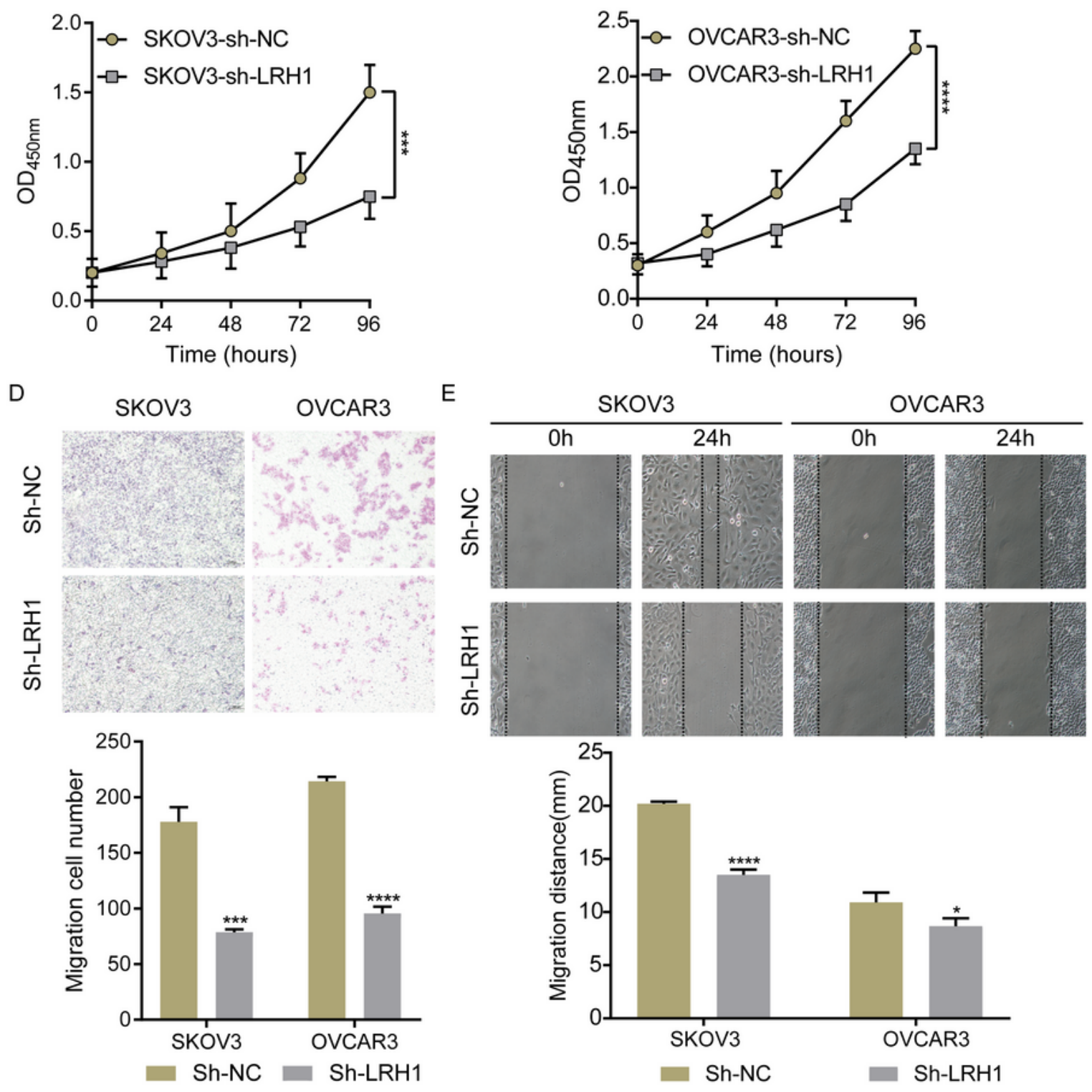

\section{Figure 4}

Knockdown of LRH1 inhibits ovarian cancer cells proliferation and migration in vitro. The level of mRNA $(A)$ and protein (B) expression significantly decreased after sh-LRH1 transfection. CCK8 assays (C) have revealed that knockdown of $\mathrm{LRH} 1$ inhibits cell proliferation. Transwell assays (D) and wound healing

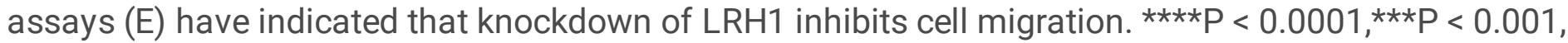
${ }^{*} \mathrm{P}<0.01, * \mathrm{P}<0.05$; data are shown as the mean $\pm \mathrm{SD}$. 